\title{
Dramatização de Histórias Infantis e a Compreensão de Leitura por Crianças Institucionalizadas ${ }^{1}$
}

\author{
Lucila Rosa Matte Massignani \\ Alessandra Rodrigues Oliveira \\ Olga Mitisue Kubo ${ }^{2}$ \\ Silvio Paulo Botomé \\ Universidade Federal de Santa Catarina
}

\begin{abstract}
RESUMO - Para aferir qual o efeito da dramatização de histórias sobre o grau de compreensão delas foi feito um experimento envolvendo 12 crianças alfabetizadas, com idades entre 7 e 10 anos. Foram divididas em duplas e remanejadas segundo delineamento de grupo, em dois tipos de atividades: leitura de histórias e exposição às histórias dramatizadas. Para a avaliação da compreensão das histórias foram solicitados: reprodução oral, respostas a perguntas literais e inferenciais, desenho e exemplificação de palavras-chave. A quantidade de respostas desconexas foi maior na condição de leitura do que na de dramatização da história. É possível concluir que expor-se à história dramatizada favorece a melhor compreensão pelos participantes, em comparação com os seus desempenhos quando a história é somente lida.
\end{abstract}

Palavras-chave: Compreensão de leitura, dramatização de histórias, recurso para ensino, estímulos sonoros e visuais.

\section{Dramatization of Children's Stories and Reading Comprehension of Institutionalized Children}

\begin{abstract}
To measure the effect of story dramatization on the level of story comprehension an experiment was carried out with 12 children varying in age between 7 and 10 years old. Subjects were split in couples and ordered in a group design, and engaged alternately in two types of activities: listening to and watching dramatized stories. The assessment was based on: oral reproduction of story, answering literal and inferential questions, drawings, and creation of story key-words. The number of disjointed answers was higher in the situation of listening to the story, in comparison to watching it. It is concluded that watching dramatized stories favors better story comprehension of children, in comparison with their performances when only listening to the story.
\end{abstract}

Key-words: reading comprehension, story dramatization, teaching resource, visual and sound stimuli.

Ler corretamente se limita a decodificar palavras? Vários autores e estudos indicam que ler é mais que decodificar palavras. Ler implica em um processo compreensivo que deve chegar às idéias centrais, às inferências, às conclusões (Cattani \& Aguiar, 1982). Segundo Pizani, Pimentel e Zunino (1998, p. 92) "além dos símbolos, existe uma mensagem que alguém teve a intenção de transmitir por meio da escrita e será o leitor, quem se encarregará de descobrir". Dessa forma, mostra-se importante conhecer as especificidades do processo de compreensão de leitura, visto que este não é um comportamento simples de ser desenvolvido.

Para compreender o que se lê, não basta decodificar símbolos, mas abranger todos os aspectos essenciais do que está sendo representado, desde os elementos literais aos inferenciais. Desse modo, a representação construída pelos leitores ao compreender um discurso escrito contém tanto informações que estão expressas explicitamente no texto,

1 Pesquisa foi financiada pelo Programa Institucional de Bolsas de Iniciação Científica (PIBIC) promovido pelo CNPq (Conselho Nacional de Desenvolvimento Científico e Tecnológico). Sílvio Paulo Botomé - bolsista produtividade do CNPq.

2 Endereço para correspondência: Núcleo de Estudos em Análise e Síntese do Comportamento - Departamento de Psicologia - Centro de Filosofia e Ciência Humanas (CFH) - Universidade Federal de Santa Catarina (UFSC) - Campus Universitário - Trindade, Florianópolis, SC - CEP 88040-970. consideradas literais, como informações que não estão no mesmo, mas que podem ser depreendidas do texto a partir de suas bases, chamadas de inferenciais (Ferreira \& Dias, 2002a). Estas possuem um papel essencial na compreensão de leitura (Brandão \& Spinillo, 1998; Ferreira \& Dias, 2002a), pois é o processo inferencial que vai permitir e garantir a organização dos sentidos elaborados pelo indivíduo na sua relação com o texto (Ferreira \& Dias, 2004).

Compreender o que se lê, além de ser um comportamento que requer aprendizagens lingüísticas, exige ainda, segundo Brandão e Spinillo (1998), traduzir as palavras em conhecimento ou significados. Ou seja, é um processo de negociação de sentidos gerado a partir dos significados conferidos pelo autor e recontextualizado pelo leitor. É este que atribui significados e que implica, por meio da interpretação, na coerência textual (Ferreira \& Dias, 2004). Nesse sentido, a habilidade de compreensão é influenciada por vários aspectos - biológicos, psicológicos, sociais, culturais - inerentes ao processo de desenvolvimento de um indivíduo, que irão determinar a forma do leitor pensar, agir, sentir e compreender o mundo.

Algumas pesquisas possibilitam mostrar a importância de desenvolver o comportamento de compreensão de leitura em crianças (Spinillo \& Martins, 1997; Brandão \& Spinillo, 1998; Brandão \& Spinillo, 2001; Salles \& Parente, 2004), como também, constatam que esta pode ser desenvolvida por 
meio do uso de algum recurso ou estratégia que contribui para o aprimoramento dessa competência (Dias, 2000; Ferreira \& Dias, 2002a; Fontes \& Cardoso-Martins, 2004). Por exemplo, o estudo de Ferreira e Dias (2002a) verificou que as crianças que participaram de treinamento para o uso de estratégias de tomar notas e de imagem mental obtiveram maior êxito na tarefa de compreensão de leitura proposta do que aquelas que dele não participaram. Assim, esses autores sugerem a instrução para o uso dessas estratégias que se constituem como um instrumento promotor de compreensão de leitura.

Dias (2000), ao avaliar a habilidade de raciocínio silogístico por meio do contar história e de discussão das mesmas com 30 crianças, argumenta que a realização destas pode ser um meio eficiente para desenvolver habilidades de raciocínio em crianças e compreensão de leitura. Da mesma forma, Fontes e Cardoso-Martins (2004) investigaram o impacto de um programa de leitura de histórias no desenvolvimento de habilidades da linguagem oral e escrita de crianças de nível sócio-econômico desfavorável e recomendam, a partir dos resultados do estudo, o uso de programas interativos de leitura de histórias, pois estes podem ter um impacto positivo no desenvolvimento de compreensão de história e no vocabulário dessas crianças. Dessa maneira, é possível perceber que existem recursos para desenvolver habilidade de compreensão de leitura com o uso da leitura de história.

A preocupação pela busca de artifícios que auxiliem as crianças a serem leitores competentes provém, especialmente, da constatação de que crianças e jovens brasileiros são leitores menos competentes do que os de outros países avaliados e de que os determinantes da baixa competência transcendem os limites das classes sociais. É o que mostra a pesquisa feita pelo Instituto Nacional de Estudos e Pesquisas Educacionais (INEP 2000/MEC) (Brasil, 2001), no qual é perceptível a deficiente capacidade do leitor brasileiro em decifrar um texto escrito. Esse resultado pode ser atribuído menos ao baixo nível sócio econômico e mais a falhas metodológicas de ensino da escola desde as séries iniciais. Nesse estudo, a aplicação do teste PISA (Program for International Student Assessment) possibilitou comparar o nível de competência de leitura de alunos de 32 países. Dentre esses, o Brasil ocupou o último lugar. $\mathrm{O}$ resultado foi que tanto alunos de escola privada quanto pública compreendem menos que os leitores de outros países.

Vale ressaltar que em 2003, 2006 e 2009 foi realizada novamente a mesma pesquisa envolvendo outros países (Brasil, 2003) na qual o Brasil manteve o mesmo desempenho na categoria "Leitura" (Brasil, 2006). Segundo os resultados internacionais da pesquisa, a educação brasileira evoluiu 33 pontos entre os exames do PISA de 2000 e 2009. Apesar da melhora, o Brasil ainda ocupa o $53^{\circ}$ lugar no ranking geral, num total de 65 países que fizeram o exame (Brasil, 2009). Esse resultado não surpreende, apenas comprova estatisticamente o que já se sabia: os brasileiros ou não sabem ler ou não compreendem o que lêem, independentemente de serem formados em escola pública ou privada.

O resultado do estudo realizado pelo INEP (Brasil, 2009) não é novidade quando se leva em consideração a realidade das escolas públicas que funcionam com dificuldades financeiras, com pouco incentivo e investimento por parte do governo. O que surpreende é o baixo desempenho apresentado pelos alunos de escolas privadas na pesquisa do INEP/MEC (Brasil, 2001). Segundo essa pesquisa, a porcentagem de alunos brasileiros de escolas privadas que apresentam a habilidade de compreender o que lê é muito pequena (1\%) comparada a outros países $(6 \%$ da Coréia e $13 \%$ dos EUA). Apesar de não serem apresentados desempenhos de estudantes que possibilitem comparações dessa natureza em pesquisas subsequentes, é importante ressaltar o quanto a dificuldade de compreensão de leitura parece estar desvinculada do aspecto do ensino ser público ou privado. A partir desses dados supõe-se que os outros países, em geral, possuam suporte necessário para uma melhor qualidade de ensino quando comparada à das escolas públicas, mas o baixo rendimento dos seus alunos pode ser revelador de um problema na qualificação de seu ensino.

Segundo Ferreira e Dias (2002b, p. 48), “faz-se necessário uma conscientização da sociedade em relação à importância da linguagem escrita, a qual pode começar a partir de uma mudança no projeto político de escola e na concretização de uma proposta social de leitura". Por outro lado, esses autores arrematam que para que haja uma revolução no aprendizado da leitura é demandada uma mudança de concepção dos professores sobre a aprendizagem da leitura e do seu ensino, a partir de uma aproximação e reflexão sobre o conhecimento produzido a respeito dos processos envolvidos nesse aprendizado. Assim, existem estratégias para melhorar a qualidade do ensino e aprendizagem, mas que ainda se deparam com obstáculos do contexto sócio-econômico e cultural em que o país está inserido.

Há pesquisas que possibilitam evidenciar problemas referentes à formação dos professores, da escola e da família, que influenciam direta ou indiretamente no desenvolvimento da habilidade de compreensão de leituras de crianças (Bordini \& Aguiar, 1988; Lins e Silva \& Spinillo, 1998; Lins e Silva \& Spinillo, 2000; Ferreira \& Dias, 2002a). No estudo realizado por Lins e Silva e Spinillo (1998), em que foi verificada a diferença na habilidade de produção escrita de histórias de crianças nas séries iniciais em escolas públicas e privadas foi constatado que a habilidade narrativa melhorava com o decorrer dos anos após a alfabetização. Porém, os alunos dos dois tipos de escolas demonstraram que a alfabetização não garante a produção de histórias mais elaboradas. Segundo essas autoras, a utilização das práticas pedagógicas pelos professores parece pressupor que o "domínio" de ler e escrever corretamente já existe ou não o privilegiam de forma apropriada.

A conseqüência disso é o que Rego (1988) denomina de analfabetismo funcional, que se caracteriza como dificuldades das pessoas na compreensão de textos escritos e revelam-se extremamente limitadas em termos de redação, embora consideradas alfabetizadas. Dessa forma, é possível concluir que há uma lacuna na formação de professores que reflete em seus procedimentos pedagógicos para formar leitores competentes, tanto em escolas privadas, quanto nas escolas públicas.

Considerar que há um problema na formação de professores também pode ser comprovado por meio de um estudo realizado por Bordini e Aguiar (1988) acerca das condições e problemas de ensino de literatura nas escolas públicas e privadas do Rio Grande do Sul. De acordo com esses autores, 
os professores, apesar de visarem a formação do hábito da leitura, geralmente não ofereciam atividades, nem utilizavam recursos que possibilitaram a expansão do conhecimento, das habilidades intelectuais e da criatividade de seus alunos.

Apesar do estudo se referir a condição presente nos últimos anos da década de 1980, há dados de avaliação de desempenho de alunos e do ensino $\left(\mathrm{SAEB}^{3}, \mathrm{ENEM}^{4}\right.$, Prova Brasi $^{5}{ }^{5}$ ) que possibilitam conjeturar que essas condições não foram modificadas substantivamente. Scholze (2004), que examina essa condição a partir de pesquisas desenvolvidas pelo INEP e da literatura científica, ressalta que a formação dos professores ainda precisa ser aprimorada, desde o letramento de seus alunos durante a licenciatura, para que se possa desenvolver o gosto pela leitura e a valorização posterior do mesmo nas salas de aula. Dessa forma, é possível perceber que a qualificação do ensino não está permitindo o desenvolvimento de leitores, na medida em que os professores não estejam capacitados para tal intento.

Para complementar, os autores Bordini e Aguiar (1988) concluíram que as atividades repetitivas, com alta carga de obrigatoriedade, como a simples leitura de texto, redações dissertativas e fichas de leitura desviam o objetivo inicial dos professores de incentivar comportamentos críticos e participativos dos alunos. A situação agrava-se ainda mais pelo uso dominante do livro didático, o qual oferece apenas fragmentos de textos que são estudados do ponto de vista gramatical. Desse modo, é possível inferir que quando o livro não possibilita estimular a reflexão crítica do leitor pode dificultar a apreensão de novos conceitos e, conseqüentemente, a compreensão de leitura. Sendo assim, Ferreira e Dias (2002a) reforçam que

para que a escola ensine a criança a superar as suas dificuldades de compreensão e a ler proficientemente, faz-se necessário, ainda, que ela abandone as antigas concepções de leitura cristalizadas ao longo do tempo, substituindo a idéia de leitura como decodificação e a idéia do mito da única interpretação válida pela concepção da leitura ligada à construção de significados múltiplos e, portanto, como atividade social, polissêmica e individual (p. 60).

Nesse sentido, também para a perspectiva comportamental, compreender o que se lê não ocorre necessariamente com a decodificação do texto. Segundo Baptista (2005), além deste, denominado por Skinner (1957/1992) de comportamento textual, outras variáveis também interferem no processo de compreensão, como: o conhecimento da escrita, os estímulos do ambiente para desenvolver habilidades necessárias para ler, a aprendizagem de aspectos semânticos e fonológicos, a familiaridade com o texto, dentre outras. Tecnicamente, Skinner (1957/1992) esclarece como ocorrem tais variáveis na compreensão de leitura e as menciona como algo que extrapola o comportamento textual, já que decorre, provavelmente, do fato de depender de outros processos comportamentais (Baptista, 2005). Como o efeito da compreensão está sujeito a diversos determinantes, principalmente das condições parti-

3 Sistema Nacional de Avaliação da Educação Básica (Brasil, 2005/2007).

4 Exame Nacional do Ensino Médio (Brasil, 2008).

5 Avaliação do sistema de ensino (Gremaud, Felicio \& Biondi, 2007). culares de cada ouvinte, então compreender o que se lê e o que se ouve varia de acordo com o repertório e contingências que reforçam o desenvolvimento desse comportamento, sendo, portanto, distinto e único para cada individuo, ao encontro do que Ferreira e Dias (2002a) afirmam.

O papel da escola na formação do leitor e escritor competente, no cumprimento do seu papel, necessitará suprir os obstáculos que existem na formação das crianças. Isto pode ser justificado pelos resultados obtidos por Lins e Silva e Spinillo (1998) que chamam atenção pelo menos para um aspecto: o ambiente familiar como um fator diferencial do desempenho das crianças de distintas classes sociais. Identificou-se que no fim dos três anos após a alfabetização crianças de classe média, mesmo submetidas à mesma metodologia de ensino, escreviam histórias mais elaboradas que crianças de classes sociais menos favorecidas. A explicação plausível encontrada pelas autoras é de que as crianças de contexto sócio-econômico desfavorecido, geralmente, não encontram no ambiente familiar respaldo suficiente para uma prática literária. Pode-se deduzir que nessas famílias, em geral, não se lê nem se escreve muito, o contato com textos narrativos é quase nulo e raramente há livros infantis em casa.

Levando-se em consideração a realidade das crianças que tem pouco acesso ao livro literário, é importante por parte dos profissionais e da escola incentivar a leitura não só do livro didático, mas principalmente do livro literário, visto que este influencia no desenvolvimento da criança e apresenta aspectos imprescindíveis no aprendizado da compreensão do que se lê. "Da prática da leitura advém uma série de conseqüências, as quais envolvem tanto o domínio cognitivo do aluno, como suas emoções e preferências, já que o livro, quando de ficção ou poesia, entra com sentidos múltiplos na intimidade de cada indivíduo" (Zilberman, 1982, p. 7).

Uma alternativa para formar um leitor competente, segundo Bordini e Aguiar (1988), poderia ser a implementação do material literário nas salas de aula. As leituras de texto literário são importantes recursos que, além de estimular a fantasia do leitor, suscitam um desenvolvimento cognitivo, uma vez que o mundo representado no texto, mesmo afastado no tempo ou diferenciado como invenção, leva o leitor a refletir sobre sua rotina e a desenvolver novas experiências e conceitos (Zilberman \& Silva, 1990). Vale lembrar que, de acordo com Bordini e Aguiar (1988), essas são condições necessárias para intensificar a compreensão de leitura, pois a literatura, como forma de expressão, quando se utiliza a linguagem verbal, envolve a particularidade dessa na construção de um mundo coerente e compreensível.

Além de todos os benefícios advindos do comportamento de ler, existe um recurso para tornar o conhecimento mais acessível por meio do contar histórias. Segundo Souza e Freitas (2007) a leitura de textos literários, entre os alunos de uma sala de aula, permite-lhes desenvolver um repertório lexical e enciclopédico e, ao mesmo tempo, torna-se mais ativa a compreensão e a facilidade de inferir algo a partir do que se lê. Vale lembrar que "existe uma acentuada diferença entre as histórias contadas e as histórias lidas para uma criança, já que a linguagem se reveste de qualidade estética quando escrita, e essa diferença já pode ser percebida por ela" (Simões, 2000, p.23). Assim, pressupõe-se que contar histórias proporciona a compreensão da leitura, pois ao verbalizar a 
história, o contador tem a possibilidade de entonar a voz de acordo com os sinais de pontuação do texto (exclamações, interrogações, marcadores de diálogo) e de expressar corporalmente, principalmente por meio de expressões faciais, os sentimentos dos personagens e sobre os acontecimentos da história (Debus, 2000; Dohme, 2000; Sisto, 2001).

"É ouvindo histórias (lidas e também contadas livremente, inspiradas na literatura ou na experiência vivida) e vendo ouvidas as suas próprias histórias que [as crianças] aprendem desde muito cedo a tecer narrativamente sua experiência, e ao fazê-lo vão se constituindo como sujeitos culturais" (Girardello, 2004, p.10). No contar histórias é possível "dar vida aos personagens" por meio da dramatização, utilizando-se da fantasia, da música e do cenário, permitindo que cada espectador desenvolva compreensão da história, facilitando a visualização de palavras abstratas e, portanto, facilitando compreender o que se lê. Por essas razões, é imprescindível investir em recursos que viabilizem a leitura de livros literários, já que estes estimulam o caráter interpretativo e a imaginação, e, principalmente, possibilita o indivíduo desenvolver aptidão para compreensão de leitura (Santos, 2009; Magalhães, 2008; Santos, Marques \& Miranda, 2007; Sisto, 2001; Girardello, 2000; Simões, 2000; Zilberman \& Silva, 1990).

Souza e Freitas (2007) realizaram um estudo com 16 crianças do quarto ano de escolaridade em uma escola básica em Portugal e investigaram as relações entre a leitura, o jogo dramático e a literatura, bem como a contribuição da utilização do jogo dramático em sala de aula para possibilitar a formação do leitor competente. Esse estudo possibilitou mostrar que o jogo dramático e a representação teatral permitem um ensino mais atraente, pelo elevado grau de interesse e envolvimento que as crianças revelaram durante as atividades desenvolvidas. Segundo esses autores, o texto dramático proporcionou aos alunos uma aventura por meio da "magia" da linguagem, desencadeando relações entre a fantasia e a realidade, e entre o mundo imaginário e o mundo empírico histórico-factual. Mesmo porque, "é através da prática dessas leituras que todos os alunos podem realizar a sua representação com sucesso e, assim, aumentar a sua auto-estima; podem construir uma base de confiança em si e, consequentemente, adquirir gosto e motivação para a leitura" (Souza \& Freitas, 2007, p.15).

As descobertas feitas por diferentes autores sobre a importância do contar e do dramatizar histórias infantis no desenvolvimento da compreensão de leitura (Santos, Marques \& Miranda, 2007; Souza \& Freitas, 2007), indicam a necessidade de mais investimentos nos estudos sobre os efeitos dessa relação no comportamento da criança em idade escolar. Assim, foi o objetivo deste estudo avaliar um recurso metodológico para promover a compreensão do que se lê e se ouve por meio de uma investigação científica que forneça bases mais sólidas à prática do ensino e aprendizagem em sala de aula.

\section{Método}

\section{Participantes}

Um total de 12 crianças foram selecionadas - 10 meninas e 2 meninos, com idades entre 7 e 10 anos, alfabetizadas (cursavam as três séries iniciais do ensino fundamental). As crianças estavam matriculadas em um centro de atendimento, municipal e gratuito, o qual atende a crianças, adolescentes e famílias carentes em um município do Estado de Santa Catarina.

\section{Material}

As atividades foram realizadas em um auditório ou em uma sala de aula, dependendo da disponibilidade no dia da atividade planejada para os participantes.

Um total de 20 livros de histórias dentre o acervo da instituição foram selecionados, segundo os seguintes critérios: grau de complexidade apropriada ao nível de escolaridade das crianças; histórias já consagradas, como os clássicos infantis; histórias com frases curtas e com figuras; histórias mais apropriadas para a dramatização, isto é, que possibilitassem execução de acordo com os recursos disponíveis (pessoais e da instituição); histórias que apresentem uma estrutura clara (início, meio e fim) e uma "moral". Após a separação dos livros, o grupo de 12 participantes escolheu 10 de acordo com suas preferências.

\section{Procedimento}

A escolha dos participantes foi baseada em critérios voltados para a faixa-etária e nível de alfabetização. Foram selecionadas as crianças que apresentaram habilidades de leitura semelhantes segundo avaliação pedagógica feita por professores e coordenadores da própria instituição.

Os participantes foram divididos em duplas e remanejados segundo um delineamento de grupo. Esse delineamento consistiu em separar as atividades de ler histórias e dramatizar, de modo que os grupos participaram de cada atividade de forma alternada. Assim, três duplas participaram da atividade de ler histórias e as outras três da dramatização, alternadamente. Cada grupo foi formado por duas crianças, agrupadas por critério de proximidade de idade: G1 Isabel e Beatriz; G2 Simone e Rosana; G3 Roberta e Fábio; G4 Iara e Alex; G5 Carla e Pricila e, G6 Sandra e Joana (os nomes das crianças são fictícios).

Foram realizadas 16 sessões: oito com leitura de histórias e oito com dramatizações, nas quais foram utilizadas oito dentre as 10 histórias escolhidas pelas crianças. As histórias foram lidas e depois dramatizadas, ambas pelas pesquisadoras, alternadamente, para grupos distintos. As dramatizações foram realizadas em forma de teatro, com a participação de outras pessoas alheias à instituição, previamente convidadas, para as histórias que exigiam mais do que duas personagens no palco.

Ao final de cada sessão foram solicitadas às crianças, como forma de avaliar o nível de compreensão das histórias lidas e dramatizadas, as tarefas individuais: (1) Desenhar sobre a história lida ou dramatizada; (2) Reproduzir oralmente a história com o auxílio do desenho; (3) Responder perguntas literais e inferenciais sobre o que foi lido ou dramatizado; (4) Exemplificar com o uso de palavras-chave. Os dados obtidos foram registrados por gravador e depois transcritos literalmente e, também foram feitas as filmagens das sessões 


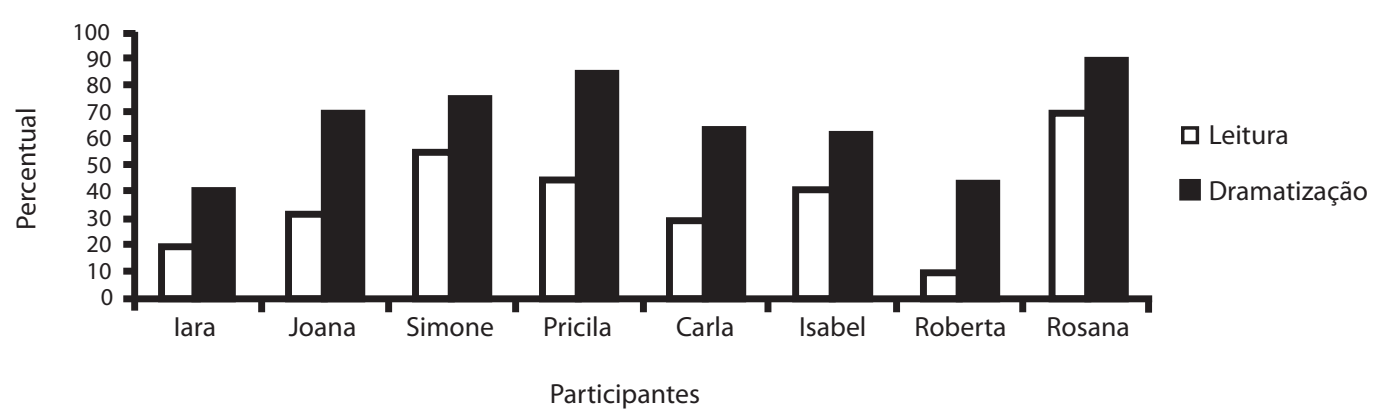

Figura 1. Distribuição da média dos percentuais de respostas literais e inferenciais de histórias lidas e dramatizadas enquadradas nas categorias A e B somadas (respostas corretas completas e incompletas), para cada participante.

de dramatização. Essas filmagens serviam como auxílio na avaliação dos resultados.

O desempenho das crianças foi analisado por meio de cinco diferentes estratégias: (1) Desenho: avaliado com os seguintes critérios: a) grau em que aparecem aspectos fundamentais da história lida ou dramatizada; b) grau de aproximação do que está representado à história lida ou dramatizada; c) grau de relação entre a história que foi lida ou dramatizada e acontecimentos pessoais; (2) Reprodução oral da história: grau de aproximação da história lida ou dramatizada e sua relação com o desenho feito; (3) Respostas literais sobre o que foi lido ou dramatizado: grau de aproximação da história lida ou dramatizada (personagens, diálogos, enredo, etc.); (4) Respostas inferenciais ao que foi lido ou dramatizado: natureza das relações estabelecidas entre os elementos da história dramatizada e outros aspectos da vida da criança ou das situações em que vive; (5) Exemplos de palavras-chave da história lida ou dramatizada: grau de coerência dos exemplos dados com a natureza e significados das palavras-chave da história.

As respostas literais e inferenciais sobre o que foi lido ou dramatizado foram avaliadas e separadas em categorias de acordo com o grau de pertinência da resposta com a história. Essas categorias foram baseadas na pesquisa de Brandão e Spinillo (1998) que as elaborou para avaliar as relações entre os enunciados, entre estes e a história ouvida, o tipo de informação reproduzida, e como estas informações estavam articuladas na reconstituição da história original.

As cinco categorias elaboradas foram: Categoria $A-$ Resposta correta e completa; Categoria B - Resposta correta, porém incompleta; Categoria $C$ - Respostas presentes na história, mas que não respondem a pergunta; Categoria D Respostas com alguns exemplos da história, com acréscimos de informações ausentes na história; Categoria E-Respostas desconexas da história e respostas tipo "não sei" ou "não lembro".

Para a análise dos desenhos foram utilizadas as categorias: Categoria I-Elementos do desenho incoerentes com a história; Categoria II - Desenhos incompletos (com menos de três elementos da história), acrescidos de informações ausentes na história; Categoria III - Desenhos incompletos (com menos de três elementos da história), sem acréscimo de informações ausentes na história; Categoria IV - Desenhos completos (com três ou mais elementos da história), acrescidos de informações ausentes; Categoria V-Desenhos completos (com três ou mais elementos da história) e coerentes com a história.
Todos os aspectos da pesquisa foram desenvolvidos sob o cuidado ético, seguindo as normas da resolução 196/96 do Conselho Nacional de Saúde. Em função disto, o Termo de Consentimento Livre e Esclarecido apresentava todas as informações a respeito da pesquisa, das condições de participação e do comprometimento do pesquisador para com os participantes. O projeto obteve aprovação do Comitê de Ética da instituição na qual foi feita a coleta de dados.

\section{Resultados}

Dentre as formas de avaliação da compreensão dos participantes a respeito do que foi lido ou dramatizado, as respostas de perguntas literais e inferenciais foram as que possibilitaram um diferencial na avaliação dos resultados. As outras formas de avaliação (desenho, reprodução oral da história e exemplificar palavras-chave) serviram como um complemento aos resultados obtidos.

Na Figura 1 os resultados apresentados das somas de duas categorias reforçam o quanto os percentuais de acertos são maiores na condição de dramatização do que na condição de história lida. Pode-se perceber que para alguns participantes essa diferença de acertos nas duas condições foi menor (em torno de $20 \%$ ), mas não menos significativo.

A soma das categorias D e E demonstra o quanto as respostas desconexas da história foram maiores na condição de leitura em comparação com a condição dramatizada (Figura 2). As diferenças dos percentuais de respostas corretas e de respostas desconexas em ambas as condições foram significativas para a maioria dos participantes.

Os desenhos das histórias lidas e dramatizadas foram classificados de acordo com a coerência e a presença de elementos da história para cada pessoa. Para a maioria dos participantes, na condição de dramatizar, os desenhos se enquadraram nas categorias IV e V, ou seja, com elementos completos e coerentes com a história, e/ou com alguns elementos ausentes. Somente três participantes obtiveram no desenho elementos completos e coerentes (Categoria V) na condição de ler a história. Geralmente, os desenhos considerados incompletos e incoerentes ocorreram nas situações de leitura da história. Vale ressaltar que alguns participantes, no caso Joana, Simone e Pricila, foram bem nas duas condições. Mas, ainda assim, apresentaram elementos mais completos e coerentes na situação de dramatização, em comparação com a leitura da história. 


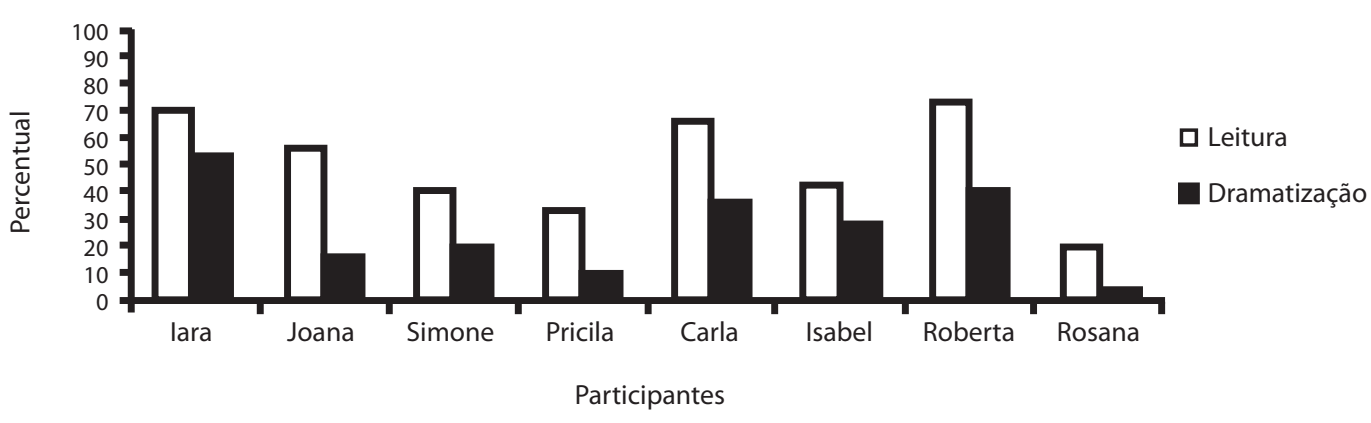

Figura 2. Distribuição da média dos percentuais de respostas literais e inferenciais de histórias lidas e dramatizadas enquadradas nas categorias D e E somadas (respostas desconexas da história e resposta com alguns exemplos da história, com acréscimos de informações ausentes na história), para cada participante.

\section{Discussão}

A partir dos resultados obtidos pode-se constatar que o uso da dramatização de histórias infantis pode melhorar o nível de compreensão de leitura de crianças. A constatação baseou-se principalmente nos resultados alcançados com a avaliação de respostas literais e inferenciais dadas pelas crianças sobre o que foi lido ou dramatizado.

Os resultados apresentados sugerem que quanto maior a porcentagem de respostas literais e inferenciais enquadradas nas categorias D e E, menor índice de compreensão pode ser inferido. O que se pode deduzir é que o número de respostas desconexas da história é mais presente quando a história é lida do que quando a história é dramatizada.

Dessa forma, pode-se constatar que o nível de compreensão é maior nas histórias dramatizadas que nas histórias contadas. Isso é perceptível nos resultados apresentados por todos os participantes. Segundo Romaña (1985), o método ativo, como no caso a dramatização, auxilia o aluno a elaborar, além de uma idéia, também uma imagem. "Uma metodologia passiva leva à transmissão de imagens não relacionadas operatoriamente com as idéias que as pessoas (alunos) estão pensando. O contrário ocorre numa metodologia ativa, onde o aluno vai fazendo, imaginando e pensando" (Romaña, 1985, p.31).

Os resultados apontam para a importância de desenvolver o comportamento de compreensão de leitura em crianças por meio do uso de algum recurso ou estratégia, como a dramatização de histórias, que contribuiu para o aprimoramento dessa competência. O que vai ao encontro da pesquisa de Ferreira e Dias (2002a) que concluiu o quanto o uso de estratégias de leitura pode ajudar na superação de dificuldades de compreensão de texto, especialmente quando possibilita a participação ativa do leitor com o texto, favorecendo a integração das informações nele contidas e a construção de inferências.

Em relação à reprodução de histórias, de acordo com Brandão e Spinillo (1998), ao reproduzir uma história é preciso, em certo sentido, selecionar os aspectos do texto original que são relevantes a serem reproduzidos, bem como as relações essenciais entre esses aspectos. Segundo os autores, em cada tarefa há habilidades distintas sendo avaliadas, e no caso da reprodução examinam-se habilidades de compreensão mais amplas e integradoras. Por meio das perguntas, avaliam-se aspectos específicos da compreensão, particulares a determinadas informações e a determinadas partes do texto (estrutura).
No entanto, o uso da reprodução da história e a exemplificação de palavras-chave como um complemento na avaliação de compreensão do que foi lido e dramatizado foi gradativamente se extinguindo nessa pesquisa. Isso ocorreu, pois poucos participantes ao serem solicitados a reproduzirem o que entenderam da história responderam, e mesmo os que responderam apresentaram dificuldades para explicar a história. Segundo Santos (2009) e Brandão e Spinillo (1998) narrar uma história, ou mesmo selecionar informações relevantes requer a capacidade de criar uma rede de relações entre os enunciados, integrando as informações neles contidas e as partes que compõem esse mesmo texto, e acionar conhecimentos do mundo e conhecimentos linguísticos. Assim, a habilidade de compreender um texto requer diferentes mecanismos cognitivos e linguísticos (Brandão \& Spinillo, 1998), todavia existem variáveis que interferem nesse processo de compreensão (Baptista, 2005). Dessa forma, as tarefas de reprodução e exemplificação exigem habilidades de compreensão mais amplas e integradoras, e para que ocorra o desenvolvimento dessa capacidade é necessário considerar os diversos aspectos, tanto individuais, quanto contextuais, que, segundo Skinner (1957/1992) e Bronfenbrenner (1979/1996) irão influenciar e reforçar o desenvolvimento desse comportamento. Segundo Spinillo e Martins (1997) a escolaridade, em particular a aquisição da leitura e da escrita, aparece como fator decisivo nesta progressão, onde crianças alfabetizadas tendem a produzir histórias mais coerentes do que crianças de mesma idade, contudo não alfabetizadas.

Entretanto, conforme Simões (2000), um dos desafios a enfrentar hoje na educação infantil é o de conseguir adaptar uma prática pedagógica voltada para atender às necessidades da criança, considerando o desenvolvimento não como um momento estanque, mas como um processo no qual a educação infantil tem um processo ativo e constitutivo. É o que mostra a pesquisa de Dias (2000), que avaliou habilidades de raciocínio silogístico usadas para alcançar conclusões e detectar incoerência em textos de 30 crianças de escolas em que contar histórias e discuti-las era freqüentemente usado (Grupo Experimental) e de 30 crianças de escolas em que essa forma de atividade era escassa (Grupo Controle). O que foi percebido é que o melhor desempenho aparece, mais facilmente, em crianças que freqüentam escolas nas quais o "contar histórias" constitui tarefa rotineira. 
No caso dos participantes desta pesquisa, pode-se deduzir que o contexto em que estão inseridos não favoreceu o desenvolvimento dos recursos cognitivos e linguísticos básicos para sentirem-se capazes de reproduzir e exemplificar palavras-chave da história lida ou dramatizada. Esse contexto em que estão inseridos perpassa pela realidade das escolas públicas brasileiras, que conforme avaliação da pesquisa do INEP (Brasil, 2009) sofre com o pouco incentivo e investimento para obter um ensino de mais qualidade. Também perpassa pela situação das famílias, as quais estão vinculadas à instituição onde foi feita a pesquisa por meio de programas sociais, que indica o fato de estarem em condições de mais vulnerabilidade social. O que vem ao encontro da pesquisa de Lins e Silva e Spinillo (1998) que observaram o quanto o ambiente familiar é fator diferencial no desempenho de crianças de distintas classes sociais. Por esses motivos, segundo Bronfenbrenner (1979/1996) é importante considerar o contexto em que a pessoa está inserida, pois é nele que ocorre o seu desenvolvimento. Diante dessa realidade, os resultados desta pesquisa mostram que apesar das dificuldades inerentes ao processo de desenvolvimento dos participantes, é possível o uso de recursos ou estratégias, no caso a dramatização de histórias, para afetar esse processo de forma benéfica.

No decorrer da pesquisa também se pôde observar que para alguns participantes houve uma melhora de seus desempenhos ao longo do tempo, isto é, o nível de compreensão aumentou progressivamente tanto na condição experimental de leitura como de exposição à dramatização da história. Por exemplo, para as participantes Simone e Pricila pode-se perceber que no decorrer das sessões foram apresentadas evoluções nos índices de respostas corretas e completas na condição experimental de leitura da história, e não apenas na condição de dramatização. Isso sugere que a criança pode aprender de forma progressiva atendo-se aos elementos da história, que são essenciais à sua compreensão. O que vai ao encontro da pesquisa de Santos (2009), que convidou crianças a contar uma história a partir da observação de um livro de imagens, demonstrando que essa evolução pode ser observada à medida que essa competência for sendo desenvolvida. De acordo com Ferreira e Dias (2004) isso parece indicar que a compreensão

\begin{abstract}
aprimora-se à medida que o sujeito participa de contextos socioculturais variados e de situações sociais envolvendo narrativas orais e/ou escritas, seja nas relações com pais e parentes próximos, seja nas relações com o professor em contexto de atividades formais de aprendizado da leitura. Aprendizado este que lhe permite tanto a expansão do vocabulário como a apropriação de situações sociais e contextos culturais variados (p. 446).
\end{abstract}

É preciso considerar ainda o desenho como um complemento para a avaliação do nível de compreensão da história, pois é comum encontrar elementos que não fazem parte da história e sim, que fazem parte do cotidiano ou da imaginação do participante. Uma vez que o desenho dá margem à imaginação, à criatividade e à espontaneidade, não necessariamente a criança vai seguir rigorosamente aos personagens e outros elementos que compõem a história ouvida ou dramatizada e, conseqüentemente, não se pode considerar o desenho com elementos ausentes da história um erro ou uma incompreensão do que foi visto ou ouvido. Ademais, o momento em que a solicitação era feita (após a dramatização, ou a leitura da história), pode se constituir em condição para a criança “criar" outros elementos relacionados ou não à história. De todo modo, conforme Simões (2000), ao ouvir uma história a criança sente estimulada sua imaginação e suas emoções, e o desenho é uma forma de expressá-las.

No decorrer da pesquisa pôde-se observar que a condição de história lida aumenta as chances de a criança agregar elementos que não pertenciam à história, já que ao ouvi-la provavelmente as condições para imaginar são ampliadas. Ao contrário, na dramatização a criança focava sua percepção naquilo que é visto, dificultando talvez diversificar o que é imaginado. Por um lado isto pode impedir a criança de imaginar (criar), mas por outro lado se ela apreende os elementos essenciais da história, o professor, em aula, poderia prover condição para diversificar histórias a partir daquela já compreendida pela criança. Contudo, segundo Simões (2000), a história literária, independentemente de textos, imagens ou sons, vai permitir à criança alimentar seu imaginário e expressá-lo, desenvolvendo a função simbólica.

Ainda que os resultados esperados tenham sido positivos, algumas dificuldades foram encontradas decorrentes das poucas condições proporcionadas pela instituição e pelas ausências dos participantes. Não é raro atividades como essas (dramatizar, ler histórias literárias) serem consideradas apenas pela dimensão lúdica, um entretenimento e não um recurso didático de incentivo à leitura (Simões, 2000; Zilberman \& Silva, 1990). Muito provavelmente, mostrar resultados alcançados nos desempenhos dessas crianças poderá constituir-se em alerta para a instituição (professor e administrador) sobre a possibilidade e a riqueza desse recurso para incrementar comportamento de ler com compreensão. No entanto, também é visível a "distância" entre ler livros literários e ler livros didáticos. Esta "passagem" necessita ser feita, assistida e com condição criada e planejada para esse fim. Isso tudo indica, a necessidade de mais estudos sobre esse processo (passagem) e os recursos necessários.

\section{Referências}

Baptista, M. Q. G. (2005). A noção de compreensão de leitura em B. F. Skinner. In E. B. Bortoli, S. R. Fiorim, \& M. L. Pinto (Eds.), Análise do comportamento: teorias e práticas (pp. $97-$ 116). Santo André (São Paulo): Esetec Editores Associados.

Bordini, M. G., \& Aguiar, V. T. (1988). Literatura: a formação do leitor: alternativas metodológicas. Porto Alegre: Mercado Aberto.

Brandão, A. C. P., \& Spinillo, A. G. (1998). Aspectos gerais e específicos na compreensão de textos. Psicologia: Reflexão e Crítica, 11, 253-272.

Brandão, A. C. P., \& Spinillo, A. G. (2001). Produção e compreensão de textos em uma perspectiva de desenvolvimento. Estudo em Psicologia. 6, 51-62. 
Brasil (2001). PISA 2000 - Program for international Student Assessment: relatório nacional. Brasília: Instituto Nacional de Estudos e Pesquisas Educacionais Anísio Teixeira (INEP), Ministério da Educação (MEC).

Brasil (2003). PISA 2003 - Program for international Student Assessment: relatório nacional. Brasília: Instituto Nacional de Estudos e Pesquisas Educacionais Anísio Teixeira (INEP), Ministério da Educação (MEC).

Brasil (2005/2007). SAEB - Sistema Nacional de Avaliação da Educação Básica. Brasília: Instituto Nacional de Estudos e Pesquisas Educacionais Anísio Teixeira (INEP), Ministério da Educação (MEC). Retrieved from http://provabrasil.inep. gov.br.

Brasil (2006). PISA 2006 - Program for international Student Assessment: resultados internacionais. Brasília: Instituto Nacional de Estudos e Pesquisas Educacionais Anísio Teixeira (INEP), Ministério da Educação (MEC).

Brasil (2008). ENEM - Exame Nacional do Ensino Médio. Brasília: Instituto Nacional de Estudos e Pesquisas Educacionais Anísio Teixeira (INEP), Ministério da Educação (MEC). Retrieved from www.enem.inep.gov.br/downloads.php.

Brasil (2009). PISA 2009 - Program for international Student Assessment: resultados preliminares. Brasília: Instituto Nacional de Estudos e Pesquisas Educacionais Anísio Teixeira (INEP), Ministério da Educação (MEC). Retrieved from http:// www.inep.gov.br/internacional/pisa.

Bronfenbrenner, U. (1996). A ecologia do desenvolvimento humano: experimentos naturais e planejados. Porto Alegre: Artes Médicas (Trabalho original publicado em 1979).

Cattani, M. I., \& Aguiar, V. T. (1982). Leitura no $1^{\circ}$ grau: a proposta dos currículos. In R. Zilberman (Ed.), A produção cultural para a criança. Porto Alegre: Mercado Aberto.

Debus, E. S. D. (2000). Contar histórias: um exercício de prazer. In Secretaria Municipal de Educação. Divisão de Educação Infantil da Prefeitura Municipal de Florianópolis (Ed.), Síntese da qualificação da educação infantil. Florianópolis: Prefeitura Municipal de Florianópolis.

Dias, M. G. B. B. (2000). Raciocínio lógico, experiência escolar e leitura com compreensão. Psicologia: Teoria e Pesquisa. $16,55-62$.

Dohme, V. D. (2000). Técnicas de contar histórias. São Paulo: Informal Editora.

Ferreira, S. P. A., \& Dias, M. G. B. B. (2002a). Compreensão de leitura: Estratégias de tomar notas e da imagem mental. Psicologia: Teoria e Pesquisa. 18, 51-62.

Ferreira, S. P. A., \& Dias, M. G. B. B. (2002b). A escola e o ensino da leitura. Psicologia em Estudo, Maringá. 7, 39-49.

Ferreira, S. P. A., \& Dias, M. G. B. B. (2004). A leitura, a produção de sentidos e o processo inferencial. Psicologia em Estudo, 9, 439-448.

Fontes, M. J. O., \& Cardoso-Martins, C. (2004). Efeitos da leitura de histórias no desenvolvimento da linguagem de crianças de nível sócio-econômico baixo. Psicologia: Reflexão $e$ Crítica. 17, 83-94.
Girardello, G. (2000). "Contando castelos no ar: as histórias e a imaginação infantil”. In Secretaria Municipal de Educação. Divisão de Educação Infantil da Prefeitura Municipal de Florianópolis (Ed.), Síntese da qualificação da educação infantil. Florianópolis: Prefeitura Municipal de Florianópolis.

Girardello, G. (2004). Voz, presença e imaginação: a narração de histórias e as crianças pequenas. Programa de Pós-Graduação em Educação da Universidade Federal de Santa Catarina. Retrieved from http://www.anped.org.br/26/trabalhos/ gilkagirardello.rtf.

Gremaud, A. P., Felicio, F., \& Biondi, R. L. (2007). Indicador de Efeito Escola: uma metodologia para a identificação dos sucessos escolares a partir dos dados da Prova Brasil. Brasília: Instituto Nacional de Estudos e Pesquisas Educacionais Anísio Teixeira (INEP), Ministério da Educação (MEC).

Lins e Silva, M. E., \& Spinillo, A. G. (1998). Uma análise comparativa da escrita de histórias pelos alunos de escolas públicas e particulares. Revista Brasileira de Estudos Pedagógicos, 79, 5-16.

Lins e Silva, M. E., \& Spinillo, A. G. (2000). A influência de diferentes situações de produção na escrita de histórias. Psicologia: Reflexão e Crítica, 13, 337-350.

Magalhães, I. O. (2008). “Era uma vez...” na educação infantil: o papel das histórias no desenvolvimento da criança. São Paulo: Faculdade Ítalo-Brasileira.

Pizani, A. P., Pimentel, M. M., \& Zunino, D. L. (1998). Compreensão da leitura e expressão escrita: a experiência pedagógica. Porto Alegre: Artes Médicas.

Rego, L. L. B. (1988). A literatura infantil: Uma nova perspectiva da alfabetização na pré-escola. São Paulo: FTD.

Romaña, M. A. (1985). Psicodrama pedagógico. Campinas: Papirus.

Salles, J. F., \& Parente, M. A. M. P. (2004). Compreensão textual em alunos de segunda e terceira séries: uma abordagem cognitiva. Estudos de Psicologia. 9, 71-80.

Santos, I. O. M. (2009). “Era uma vez...": um estudo sobre o desenvolvimento da competência narrativa em crianças. Dissertação de Mestrado, Pontifícia Universidade Católica / PUC, São Paulo.

Santos, C. M. B., Marques, J. T., Miranda, M. X. R. (2007). Literatura infantil: o despertar de um mundo novo. Retrieved from http://www.faesi.com.br/2007/ downloads/6/TCC\%20 PRONTO\%20-\%20MARIA.pdf

Scholze, L. (2004). Letramento e desenvolvimento nacional. Instituto Nacional de Estudos e Pesquisas Educacionais Anísio Teixeira (INEP): Brasília.

Simões, V. L. B. (2000). Histórias infantis e aquisição de escrita. São Paulo em Perspectiva. 14, 1-16.

Sisto, C. (2001). Textos e pretextos sobre a arte de contar histórias. Chapecó: Argos Editora Universitária. 
Souza, R. J., \& Freitas, E. R. S. S. (2007). O jogo dramático na construção da criança leitora. In Pós-graduação em Educação (Ed.), Revista Contemporânea de Educação, 6. Universidade Federal do Rio de Janeiro, Rio de Janeiro.

Skinner, B. F. (1957/1992). Verbal behavior. Cambridge: Coley Publishing.

Spinillo, A.G., \& Martins, R.A. (1997). Uma análise da produção de histórias coerentes por crianças. Psicologia: Reflexão e Crítica, 10, 219-248.

Zilberman, R. (1982). A leitura na escola. In R. Zilberman (Ed.), A produção cultural para a criança. Porto Alegre: Mercado Aberto.
Zilberman, R., \& Silva, (1990). Literatura e pedagogia: ponto e contraponto. Porto Alegre: Mercado Aberto.

Recebido em 04.12.2009

Primeira decisão editorial em 14.07.2011

Versão final em 18.07.2011

Aceito em 18.07.2011 